\title{
Original article (short paper) \\ Anthropometric analysis and performance characteristics to predict selection in young male and female handball players
}

\author{
Juan J. Fernández-Romero \\ University of A Coruña, Corunã, Spain \\ Helena Vila Suárez \\ Jose $\mathrm{M}^{\mathrm{a}}$ Cancela \\ Universidade de Vigo, Vigo, Spain
}

\begin{abstract}
The aim of this study was two-fold. The first aim was to determine if there were any anthropometric and physical performance differences (controlling for maturation) between male and female handball players selected in training categories as well as the relation of these differences with the performance level achieved. The second aim was to identify the discriminatory variables between the performance levels achieved. A total of 216 young handball players (125 men and 91 women) participated in the study. The data were classified by selection level (regional $n=154$; national $n=62$ ), gender (men; women) and age category (under-15; under-17). The use of MANCOVA analyses, controlling for maturation, identified how gender could determine variables related to handball players' future competitive levels. The results revealed that anthropometric variables such as height, arm span, trochanter height, thigh girth, and leg girth were more influential in men than in women. In addition, the physical performance tests of vertical jump (squat jump and counter movement jump with/without arm) and 10x5 m shuttle run were determinants in both gender. Discriminatory analysis predicted that a combination of five variables (counter movement jump with arm, body mass, 10x5 m shuttle run, dominant hand length and trochanter height) would successfully distinguish between regional and national players, with a predictive accuracy of $81.9 \%$ for all players.
\end{abstract}

Key words: talent, maturity, performance, $\mathrm{VO}_{2}$ max, explosive strength

\section{Introduction}

The process of a steady increase in professional sport has led to an interest in identifying prospective top players as soon as possible. For this reason, clubs spend increasing amounts of time and resources on the process of identifying and selecting young talent. This article expands on the existing relation between anthropometric characteristics, physical performance and identification of talent ${ }^{1,2}$ in young male and female handball players.

The concept of 'talent' is still very complex to pinpoint, although it has been suggested that it consists of trying to identify, right from the earliest developmental stages, which players could become elite ${ }^{3}$. In team sports, this prediction about the player's potential performance is more complex than in individual sports because of the involvement of genetic, physiological, morphological, psychological, and environmental factors ${ }^{4,5}$.Therefore, the model of talent identification, largely influenced by the particular design of individual sports, is currently being reviewed. These models make it difficult to forecast the best possible performance levels in a number of sports from a very young age and with reasonable probability levels. Over the last few years, a new focus on the study of talent identification in team sports seems to have gained pre-eminence ${ }^{2,6,7}$. Various player characteristics are quantified with the aim of uncovering a series of key factors that might facilitate early talent identification. Previous studies have assessed how anthropometric and physical performance characteristics are important to achieve outstanding levels of performance in team sports such as basketball ${ }^{8}$, soccer ${ }^{9}, 10$, rugby $^{11}$ and handball ${ }^{2,12-14}$. According to these authors, anthropometric, and physical performance characteristics are considered fundamental for talent identification. The present study expanded on these ideas and tried to determine which anthropometric and physical performance variables, by means of discriminatory analysis, were most significant at the time of selecting male and female handball players; this follows the trend of research established by other academics and practitioners ${ }^{7,15,16}$.

The aim of this study was two-fold. The first aim was to determine if there were any anthropometric and physical performance differences (controlling for maturation) between male and female handball players selected in accordance with training categories, in relation to the competitive levels achieved (either regionally or nationally). The second aim was to identify which of the variables could discriminate between the performance levels achieved.

\section{Methods}

\section{Participants}

A total of 216 young handball players (125 men and 91 women) who belonged to the Galician Handball Federation (Galicia, Spain) took part in the study. This particular federation has one of the highest numbers of teams and player licenses in the country; this provided the research team with a large enough resource pool to carry out a compelling statistical analysis.

A committee of experts consisting of five members of the technical section of the handball federation selected groups of 
participants between the ages of 12 and 17 from a total of 1,568 young players. No member of the research team was involved in this selection. The participants were assessed longitudinally during the 1998/1999 season and performance level tracking was followed up until March 2013 to try to determine the performance level they had achieved.

The data were classified according to selection level (regional $n=154$; national $n=62$ ), gender (men; women) and age category (under-15; under-17). The average age of the sample was $15.1 \pm 1.6$ years (men: $15.7 \pm 1.3$ years; women: $14.4 \pm 1.5$ years). The male national level players had played in the highest category of the Spanish Handball Federation (ASOBAL) for a minimum of the duration of a season. The female national level players fulfilled the same condition in the B Honor Division. All the other participants were classified under the label "regional level," which comprised the rest of the leagues and divisions.

All the players took part in an anthropometric and fitness assessment. All the protocols received the institutional approval of two ethics committees: the Ethics Committee of the Galician Handball Federation, and the Ethical Principles for Medical Research involving Human Objects (Declaration of Helsinki). Parental or guardian consent was also obtained.

\section{Procedures}

The players performed a battery of fitness tests at the beginning of the competitive season before their pre-season training period and as a part of their respective training programs. All the assessments were carried out by the Sport Science Department of the University of A Coruña. Standard anthropometry, maturation, and physical performance data were compiled for each participant who competed at the regional level and all the tests were completed on the same day.

Anthropometry: Anthropometric measurements were conducted, following standardized procedures by ISAK (International Society for the Advancement of Kinanthropometry), a society of certified anthropometrists ${ }^{17}$. The measurements included height, sitting height, weight, arm span, trochanter height, arm length, dominant hand length, four skinfold measurements (triceps, subscapular, supraspinal and abdominal), two breadths (biacromial and biepicondylar), and two girths (thigh and leg). The sum of the four skinfolds was used as the main adiposity index. Height and sitting height were measured using a Seca Alpha stand (Barcelona, Spain) to the nearest $0.1 \mathrm{~cm}$. Weight was measured using calibrated Seca alpha scales (model 770) to the nearest $0.01 \mathrm{~kg}$. Skinfolds were measured with a Harpenden skinfold caliper (British Indicators Ltd., Luton), with $10 \mathrm{~g} \cdot \mathrm{mm}^{-2}$ constant pressure. Girths were measured using a Lufkin Metal Tape (Lufkin Executive Thinline, W606PM, USA). Breadths and lengths were measured using an anthropometer (GPM, Siber Hegner Zurich, Switzerland) with an accuracy of $0.01 \mathrm{~cm}$.

Maturation (age at PHV): The players' maturity status was determined using Mirwald, Baxter-Jones, Bailey and Beunen's ${ }^{18}$ prediction equation. This technique is a non-invasive method that predicts years from peak height velocity (PHV) as a measure of maturity, offset using anthropometric variables.
Years from PHV was calculated by subtracting age at PHV from the player's chronological age.

Physical Performance: The EUROFIT test battery ${ }^{19}$ was used to assess general physical fitness and was applied using the official protocols and materials in the following order: 1) Shuttle run test assessed aerobic endurance; 2) Flamingo balance assessed general balance; 3) Plate tapping assessed segment velocity of the upper limbs; 4) Sit and reach assessed flexibility of the trunk and lower limbs; 5) Standing long jump assessed explosive strength of the lower limbs; 6) Hand dynamometry assessed grip; 7) Sit-ups for 30 seconds assessed trunk power; 8) Flexed arm hang assessed muscular resistance of the arms and shoulders, and; 9) Shuttle run test of 10x5 m assessed agility and speed. Additional tests were also performed by each player to calculate explosive strength.

Each participant performed three kinds of maximal jumps (Squat Jump [SJ], Countermovement Jump [CMJ] and Avalakov Jump) on a jump mat (Ergo Jump Bosco System Byomedics, SCP, Barcelona, Spain). The participants completed three trials of each type of jump, and the best one was used for the subsequent statistical analysis. Between jumps, the participants were allowed to recover for three minutes to avoid fatigue. Jump height was calculated using flight time. The SJ showed an ICC of 0.94 and a CV of $24.2 \%$, and the CMJ showed an ICC of 0.97 and a $\mathrm{CV}$ of $22.1 \%$. Aerobic capacity was expressed as estimated maximal oxygen uptake $\left(\mathrm{VO}_{2}\right.$ max) using a $20 \mathrm{~m}$ shuttle run test and predicted by a regression equation according to age and running speed at the last completed stage ${ }^{20}$. A 15 minute warm-up was performed before the physical testing.

\section{Statistical analysis}

Mean and Standard Deviation (SD) scores were calculated for all dependent variables with selection level acting as the independent variable. None of the data violated the normality assumption necessary to conduct parametric statistical tests (Kolmogorov-Smirnov; $p>0.05$ ). A multivariate analysis of covariance test (MANCOVA) was applied with selection level (regional vs. national) as the fixed factor. Maturity (years from PHV) was used as a covariate to adjust for variations in maturation status. Partial eta squared effect sizes $\left(n^{2}\right)$ were also calculated. To identify discriminating variables between regional and national players, a stepwise discriminant analysis was applied with selection level being used as the discrete outcome variable. SPSS version 15.0 was employed for all analyses with the significance set at $p<0.05$.

\section{Results}

The anthropometric characteristics and physical performance parameters of the mean and standard deviation, and taking into account the selection level (i.e., regional and national) are shown in Table 1. The results indicate that maturation age influenced players' performance level independently of sex. MANCOVA analyses between selection levels for all players revealed that 
national players outperformed regional players significantly for height, arm span, trochanter height, body mass, sum of skinfolds, thigh circumference, leg circumference, vertical jump (SJ, CMJ, and CMJ with arm Avalakov), standing broad jump, flamingo balance, plate tapping, sit and reach, sit-ups, ups, 10x5 m shuttle rum, $20 \mathrm{~m}$ shuttle run and $\mathrm{VO}_{2}$ max in male players.

Table 1. Selection level characteristics (national vs. regional) of male and female handball players

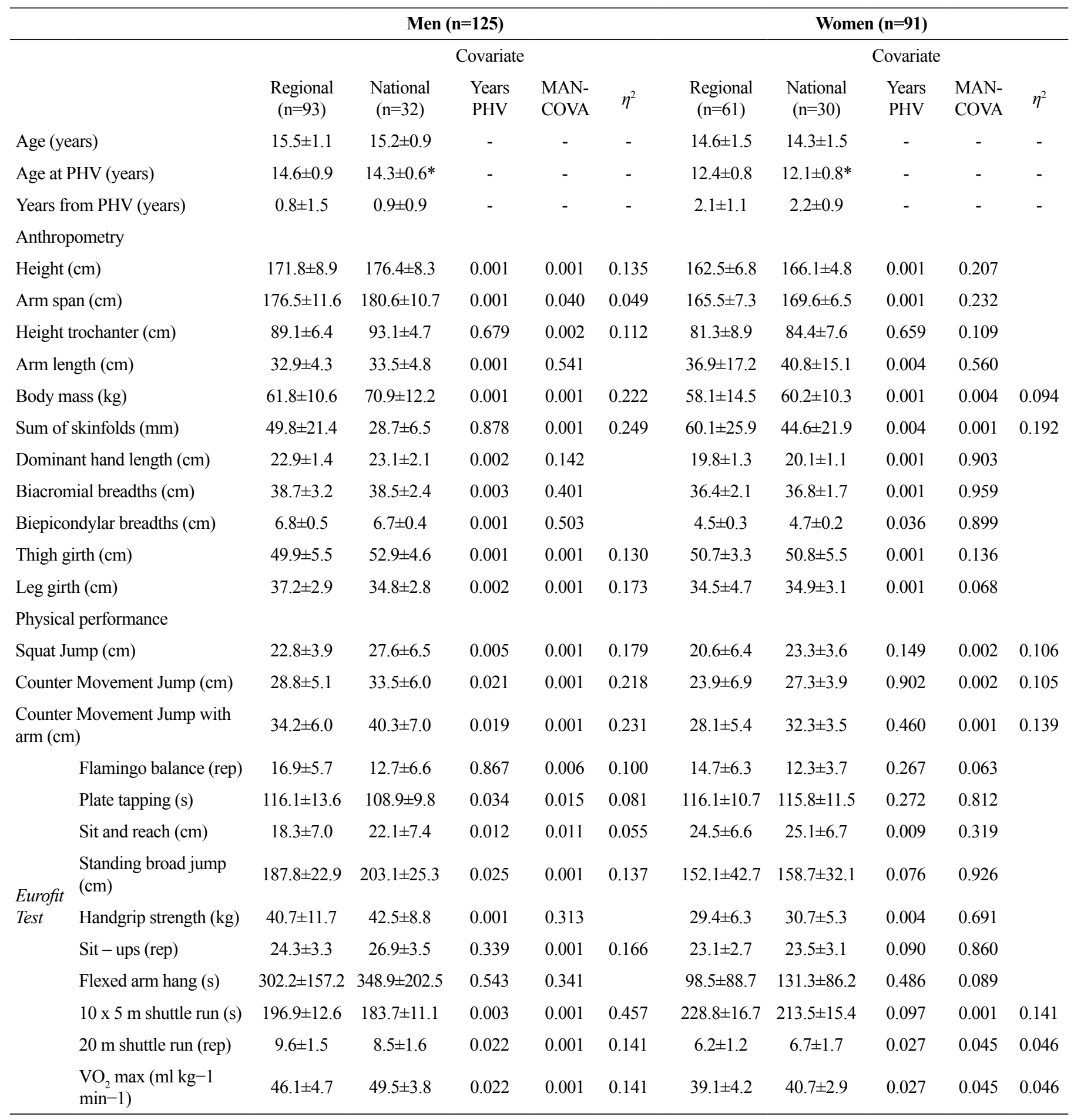

Table 2 presents the means and standard deviations of the anthropometric characteristics and physical performance of the selection level by age category (under-15 and under-17). Maturity status (PHV) did not condition players' performance levels; there were other parameters that determined these differences. The parameters that had a significant influence on players' performance level (globally and regardless of gender and age category) were the following: body mass, sum of skinfolds, explosive strength (SJ, CMJ, Avalakov jump, 10x5 $\mathrm{m}$ shuttle run) and $\mathrm{VO}_{2}$ max. 
Table 2. Mean and standard deviation of the anthropometric and conditional characteristics of male and female handball players by category and performance level

\begin{tabular}{|c|c|c|c|c|c|c|c|c|c|}
\hline & & \multicolumn{4}{|c|}{ Men $(n=125)$} & \multicolumn{4}{|c|}{ Women $(n=91)$} \\
\hline & & \multicolumn{2}{|c|}{ under-15 $(\mathrm{n}=62)$} & \multicolumn{2}{|c|}{ under-17 $(\mathrm{n}=63)$} & \multicolumn{2}{|c|}{ under-15 $(\mathrm{n}=48)$} & \multicolumn{2}{|c|}{ under-17 $(\mathrm{n}=43)$} \\
\hline & & $\begin{array}{c}\text { Regional } \\
\mathrm{n}=44\end{array}$ & $\begin{array}{c}\text { National } \\
\mathrm{n}=18\end{array}$ & $\begin{array}{c}\text { Regional } \\
\mathrm{n}=49\end{array}$ & $\begin{array}{c}\text { National } \\
\mathrm{n}=14\end{array}$ & $\begin{array}{c}\text { Regional } \\
\mathrm{n}=33\end{array}$ & $\begin{array}{c}\text { National } \\
\mathrm{n}=16\end{array}$ & $\begin{array}{c}\text { Regional } \\
\mathrm{n}=28\end{array}$ & $\begin{array}{c}\text { National } \\
\mathrm{n}=14\end{array}$ \\
\hline \multicolumn{2}{|c|}{ Age (years) } & $14.6 \pm 0.4$ & $14.6 \pm 0.6$ & $16.4 \pm 0.8$ & $16.5 \pm 0.8$ & $13.2 \pm 0.6$ & $13.3 \pm 0.8$ & $15.8 \pm 0.8$ & $15.9 \pm 0.9$ \\
\hline \multicolumn{2}{|c|}{ Age at PHV (years) } & $14.2 \pm 0.7$ & $14.6 \pm 0.5$ & $14.5 \pm 0.9$ & $14.6 \pm 0.8$ & $11.5 \pm 0.4$ & $11.9 \pm 0.6$ & $12.8 \pm 0.5$ & $13.1 \pm 0.7$ \\
\hline \multicolumn{2}{|c|}{ Years from PHV (years) } & $0.4 \pm 0.7$ & $0.1 \pm 0.1$ & $1.8 \pm 1.2$ & $1.8 \pm 1.2$ & $1.7 \pm 0.6$ & $1.4 \pm 0.9$ & $3.0 \pm 0.6$ & $2.7 \pm 1.8$ \\
\hline \multicolumn{10}{|c|}{ Anthropometry } \\
\hline \multicolumn{2}{|c|}{ Height (cm) } & $169.1 \pm 9.0$ & $173.6 \pm 7.3$ & $175.3 \pm 7.2$ & $181.4 \pm 8.6^{*}$ & $161.6 \pm 6.1$ & $163.9 \pm 10.1$ & $163.0 . \pm 5.7$ & $168.5 \pm 5.2 *$ \\
\hline \multicolumn{2}{|c|}{ Arm span $(\mathrm{cm})$} & $176.9 \pm 9.1$ & $173.4 \pm 12.9$ & $180.5 \pm 11.6$ & $187.7 \pm 7.5^{*}$ & $164.5 \pm 80.6$ & $167.3 \pm 11.2$ & $166.8 \pm 5.7$ & $172.1 \pm 2.6^{*}$ \\
\hline \multicolumn{2}{|c|}{ Height trochanter $(\mathrm{cm})$} & $89.2 \pm 5.4$ & $91.5 \pm 4.3$ & $89.1 \pm 7.3$ & $95.8 \pm 2.9^{*}$ & $76.6 \pm 6.5$ & $83.5 \pm 9.2 *$ & $85.8 \pm 4.8$ & $86.4 \pm 22.6$ \\
\hline \multicolumn{2}{|c|}{ Arm length $(\mathrm{cm})$} & $31.8 \pm 2.8$ & $32.5 \pm 5.1$ & $34.8 \pm 2.9$ & $34.8 \pm 4.6$ & $36.5 \pm 2.8$ & $36.8 \pm 5.1$ & $37.4 \pm 26.6$ & $37.5 \pm 17.3$ \\
\hline \multicolumn{2}{|c|}{ Body mass (kg) } & $66.6 \pm 11.0$ & $57.6 \pm 10.5^{*}$ & $78.5 \pm 11.6$ & $67.3 \pm 17.7 * *$ & $57.2 \pm 10.4$ & $56.3 \pm 12.9^{*}$ & $64.1 \pm 9.7$ & $60.0 \pm 4.5^{*}$ \\
\hline \multicolumn{2}{|c|}{ Sum of skinfolds (mm) } & $49.9 \pm 19.7$ & $29.3 \pm 7.1 * *$ & $48.4 \pm 16.0$ & $28.1 \pm 5.8^{* *}$ & $54.4 \pm 24.1$ & $43.1 \pm 9.2 *$ & $67.4 \pm 21.3$ & $46.2 \pm 9.5^{*}$ \\
\hline \multicolumn{2}{|c|}{ Dominant hand length (cm) } & $22.5 \pm 1.4$ & $22.3 \pm 2.1$ & $22.8 \pm 1.4$ & $24.2 \pm 1.8^{*}$ & $20.0 \pm 1.1$ & $20.0 \pm 1.3$ & $20.1 \pm 1.3$ & $20.5 \pm 1.0$ \\
\hline \multicolumn{2}{|c|}{ Biacromial breadths $(\mathrm{cm})$} & $37.2 \pm 2.4$ & $37.7 \pm 2.3$ & $39.1 \pm 2.5$ & $39.9 \pm 2.1$ & $36.0 \pm 2.9$ & $36.7 \pm 2.3$ & $36.8 \pm 1.6$ & $36.9 \pm 1.7$ \\
\hline \multicolumn{2}{|c|}{ Biepicondylar breadths (cm) } & $6.7 \pm 0.3$ & $6.7 \pm 0.5$ & $7.0 \pm 0.4$ & $6.8 \pm 0.3$ & $4.1 \pm 0.3$ & $4.3 \pm 0.3$ & $4.9 \pm 0.2$ & $5.1 \pm 0.2$ \\
\hline \multicolumn{2}{|c|}{ Thigh girth $(\mathrm{cm})$} & $48.8 \pm 4.7$ & $51.7 \pm 4.4^{*}$ & $51.3 \pm 5.8$ & $55.1 \pm 4.4^{*}$ & $49.6 \pm 4.5$ & $50.3 \pm 4.9$ & $51.1 \pm 4.4$ & $52.4 \pm 8.6$ \\
\hline \multirow{2}{*}{\multicolumn{2}{|c|}{$\begin{array}{l}\text { Leg girth }(\mathrm{cm}) \\
\text { Physical performance measures }\end{array}$}} & $33.9 \pm 3.0$ & $36.4 \pm 2.9^{*}$ & $36.0 \pm 3.5$ & $38.6 \pm 2.9^{*}$ & $34.1 \pm 4.3$ & $34.5 \pm 3.3$ & $34.5 \pm 2.6$ & $36.1 \pm 5.6^{*}$ \\
\hline & & & & & & & & & \\
\hline \multicolumn{2}{|c|}{ Squat Jump $(\mathrm{cm})$} & $22.4 \pm 5.9$ & $26.2 \pm 4.1 *$ & $23.5 \pm 7.6$ & $29.6 \pm 2.8^{*}$ & $20.4 \pm 4.1$ & $23.2 \pm 7.6^{*}$ & $20.8 \pm 3.2$ & $23.4 \pm 1.8^{*}$ \\
\hline \multicolumn{2}{|c|}{ Counter Movement Jump (cm) } & $28.3 \pm 4.9$ & $31.5 \pm 4.7 *$ & $29.7 \pm 6.9$ & $36.0 \pm 2.4^{*}$ & $23.1 \pm 8.2$ & $27.2 \pm 4.1^{*}$ & $25.2 \pm 2.9$ & $27.3 \pm 3.6^{*}$ \\
\hline \multicolumn{2}{|c|}{$\begin{array}{l}\text { Counter Movement Jump with arm } \\
(\mathrm{cm})\end{array}$} & $33.3 \pm 5.9$ & $37.5 \pm 5.8^{*}$ & $35.8 \pm 8.1$ & $43.8 \pm 5.6^{*}$ & $27.1 \pm 9.7$ & $32.2 \pm 4.4^{*}$ & $29.5 \pm 2.6$ & $32.5 \pm 3.9^{*}$ \\
\hline \multirow{10}{*}{$\begin{array}{l}\text { Eurofit } \\
\text { Test }\end{array}$} & Flamingo balance (rep) & $17.1 \pm 7.1$ & $12.6 \pm 5.6^{*}$ & $16.5 \pm 6.3$ & $12.8 \pm 3.1$ & $15.3 \pm 6.4$ & $13.4 \pm 3.8$ & $14.1 \pm 6.1$ & $11.0 \pm 3.9$ \\
\hline & Plate tapping (s) & $119.2 \pm 12.6$ & $111.5 \pm 11.1$ & $110.4 \pm 8.4$ & $105.3 \pm 13.1$ & $118.2 \pm 10.6$ & $118.5 \pm 9.8$ & $112.6 \pm 10.1$ & $113.4 \pm 19.0$ \\
\hline & Sit and reach $(\mathrm{cm})$ & $17.1 \pm 7.5$ & $21.8 \pm 4.6^{*}$ & $20.6 \pm 7.4$ & $22.3 \pm 6.1$ & $20.4 \pm 5.6$ & $23.7 \pm 6.6$ & $26.9 \pm 9.7$ & $28.9 \pm 5.7$ \\
\hline & Standing broad jump $(\mathrm{cm})$ & $181.8 \pm 21.8$ & $196.4 \pm 19.5^{*}$ & $199.6 \pm 25.2$ & $211.5 \pm 18.3$ & $143.4 \pm 38.7$ & $144.8 \pm 50.3$ & $162.9 \pm 10.8$ & $174.2 \pm 17.5$ \\
\hline & Handgrip strength (kg) & $38.1 \pm 6.9$ & $38.4 \pm 9.7$ & $45.1 \pm 8.7$ & $48.2 \pm 10.8$ & $27.8 \pm 5.8$ & $29.0 \pm 7.2$ & $31.4 \pm 3.6$ & $32.4 \pm 4.5$ \\
\hline & Sit ups (rep) & $23.6 \pm 3.6$ & $26.4 \pm 3.5^{*}$ & $25.7 \pm 2.9$ & $27.7 \pm 2.9$ & $22.3 \pm 2.9$ & $23.5 \pm 3.6$ & $24.0 \pm 2.9$ & $24.2 \pm 2.1$ \\
\hline & Flexed arm hang (s) & $295.6 \pm 215.7$ & $368.3 \pm 140.1$ & $315.0 \pm 196.9$ & $324.3 \pm 201.6$ & $93.6 \pm 90.4$ & $127.9 \pm 76.7$ & $104.9 \pm 88.2$ & $136.0 \pm 112.0$ \\
\hline & $10 \times 5 \mathrm{~m}$ shuttle run (s) & $198.9 \pm 9.2$ & $186.3 \pm 12.4^{*}$ & $193.2 \pm 9.9$ & $180.3 \pm 11.5^{*}$ & $235.8 \pm 19.1$ & $216.4 \pm 17.2^{*}$ & $220.9 \pm 10.5$ & $210.2 \pm 8.1^{*}$ \\
\hline & 20 m shuttle run (rep) & $8.3 \pm 1.7$ & $9.6 \pm 1.8^{*}$ & $8.8 \pm 1.2$ & $9.6 \pm 1.6^{*}$ & $6.1 \pm 1.4$ & $6.6 \pm 1.4^{*}$ & $6.3 \pm 1.0$ & $6.8 \pm 2.5^{*}$ \\
\hline & $\mathrm{VO}_{2} \max (\mathrm{ml} \mathrm{kg}-1 \mathrm{~min}-1)$ & $45.5 \pm 5.3$ & $49.4 \pm 4.3 *$ & $47.2 \pm 3.5$ & $49.6 \pm 3.4^{*}$ & $38.8 \pm 4.3$ & $40.3 \pm 3.7^{*}$ & $39.6 \pm 4.1$ & $41.2 \pm 1.7 *$ \\
\hline
\end{tabular}

APHV = age at peak height velocity; $* 0.005 ; * * 0.001$

Within the under-15 male category, we identified more parameters that condition performance in a significant way. These parameters were thigh and leg girth, flamingo balance, sit and reach, standing broad jump and sit-ups. In the case of female players, the only parameter incorporated was trochanter height. Regarding the under-17 male category, the following parameters were identified as determining factors of performance: height, arm span, trochanter height, dominant hand length, and thigh and leg girth. Regarding the under-17 female category, the parameters were height, arm span and leg girth.

The stepwise discriminatory analysis predicted that a combination of five variables would successfully discriminate between regional and national players: $\mathrm{CMJ}$ with arm (0.826), body mass $(0.759), 10 \times 5 \mathrm{~m}$ shuttle run $(0.701)$, dominant hand length $(0.630)$, and trochanter height $(0.599)$. The average squared canonical correlation was 0.634 , showing that these five variables accounted for $63.4 \%$ of the overall variance in the data set. Cross-validation results were calculated to identify the correct classification of regional and national players based on the discriminatory analysis. The discriminatory analysis corresponded to an overall predictive accuracy of $81.9 \%$ for all players with an accuracy of $78.9 \%$ and $87.7 \%$ for regional and national players respectively.

\section{Discussion}

The first aim of the present study was to determine if there were any anthropometric and physical performance differences (controlling for maturation) in male and female handball players selected in training categories, with relation to the competitive level achieved (regional and national). The second purpose of this study was to identify which variables could be taken into account at the time of selecting handball players to reach maximum performance levels. 
When the results are analyzed in terms of physical performance and anthropometric characteristics in the training period and ages of the players, it must be taken into consideration that performance data need to include maturation ${ }^{2}, 13,21$, ${ }^{22}$. As stated earlier, maturation is a variable that influences male and female handball players when they try to achieve their maximum performance level (national). Anthropometric characteristics, explosive strength, agility-velocity, and aerobic capacity discriminate male and female players with regard to their performance level.

In accordance with previous studies where maturation was statistically controlled ${ }^{7,15}$, we found that PHV (maturation status) influences the performance level of male and female handball players. National level handball players (male and female) show better values in both anthropometric parameters and physical performance when compared to regional level players. These differences are highly significant in the case of anthropometric parameters (height, arm span, body mass, biacromial breadth, and hand length), even though other authors have also referred to these differences as key to performance levels $2,23,24,25$.

Taking into consideration the players' gender, differences in physical performance are connected with the explosive strength of the lower limbs and with the maximum isometric strength of the forearm for male players. However, for female players the differences are found in the maximum isometric strength of the forearm and aerobic power. These results are in accordance with a study conducted by Malina, Cumming, Morano, Barron and Miller ${ }^{21}$ on the maturation of young football players.

A limited number of studies have assessed some anthropometric parameters, physical performance and maturity status in handball ${ }^{13,26}$.Mohamed, Vaeyens, Matthys, Multael, Lefevre, Lenoir and Philippaerts ${ }^{2}$ carried out a cross-sectional study with players (elite vs. non-elite) between the ages of 12 and 16, and concluded that maturation had influenced anthropometric parameters and not physical performance, except in the case of hand-grip. However, a study carried out by Matthys, Vaeyens, Vandendriessche, Vandorpe, Pion, Coutts, Lenoir and Philippaerts ${ }^{13}$ with players between the ages of 12 and 17 concluded that maturation was a determining factor in anthropometric and physical performance parameters, which coincides with the results reported in the present study. Other soccer-related studies ${ }^{15,22,27}$ have reported results that are also in line with the results obtained in the present study. Nevertheless, given the clear methodological divergences observed in these studies, such conclusions should be reflected upon carefully. Very little information is available on young female players, which renders comparisons quite challenging.

When the maturity status is statistically controlled, results show how the group with the maximum level of performance (national) presents fewer differences with regard to the regional level group, which reinforces the importance of maturity as a key factor in executing talent selection ${ }^{2,13,21,22}$, with both males and females.

Once the effect of player maturity is neutralized, it is observed how anthropometric parameters (sum of skinfolds, body mass, leg girth, height, thigh girth, trochanter height and arm span) and physical performance parameters (vertical jump SJ,
CMJ, Avalakov jump, standing broad jump, flamingo balance, plate tapping, sit and reach, sit-ups, 10x5 m shuttle run, $20 \mathrm{~m}$ shuttle run and $\mathrm{VO}_{2}$ max) are responsible for the difference in performance levels. This behavior is not shown when female players are analyzed; therefore, maturity is a fundamental factor that strongly determines performance level. The only anthropometrical variables that are not affected by maturity are weight and body fat; the latter variable is inversely correlated to performance ${ }^{23,28}$. This behavior would need to be taken into consideration in future research. Regarding physical performance parameters, the data analysis suggests that explosive strength, sprinting for short distances and aerobic capacity can discriminate across levels for female players.

The results of the study carried out by Vaeyens, Malina, Janssens., Van Renterghem, Bourgois, Vrijens and Philippaerts ${ }^{22}$ are in accordance with the results of the present study. They confirmed that anthropometric parameters, once maturity is controlled, are conditioned by the analyzed category, so the anthropometric data show differences between performance levels in 50\% of the analyzed categories (under-14 and under-15). Taking gender into consideration, maturity is a key factor for females and it determines $80 \%$ of the variables under study; in the case of male maturity, it is only $55.5 \%$. The results shown by Matthys, Vaeyens, Vandendriessche, Vandorpe, Pion, Coutts, Lenoir and Philippaerts ${ }^{13}$, which are directly linked to physical performance parameters, revealed that maturation is not the only variable responsible for the differences between handball players of different performance levels in parameters such as explosive strength, speed and agility; these parameters are also conditioned by the category that is analyzed, which also seems to be the case for females when the parameters of explosive strength, speed and aerobic resistance are considered.

The analysis carried out within each age (under-15 and under-17) and the gender group revealed that the maturity parameter does not determine performance level within each age category; the selection process carried out by the group of experts could have influenced this. These results confirm the findings presented by Till, Cobley, O'Hara, Chapman and Cooke $^{11}$. A more detailed study of each age group (under-15 and under-17) showed how the behavior of anthropometric and physical performance variables for the under- 15 category is not conditioned by gender. In fact, the parameters that best identify maximum performance are linked to physical performance (explosive strength, speed, aerobic resistance). These results coincide with those reported in Vaeyens, Malina, Janssens, Van Renterghem, Bourgois, Vrijens and Philippaerts ${ }^{22}$ for male soccer players, as well as with the study conducted by Till, Cobley, O'Hara, Chapman and Cooke ${ }^{11}$ for male rugby players. If we analyze the under-17 group, anthropometrical variables (height, arm span, body mass, sum of skinfolds, leg girth) become more predictive of handball players' performance levels, while physical performance variables remain stable in both age groups and they reassert the importance of explosive strength, speed-agility and aerobic power in handball ${ }^{2,23}$. These results are also in accordance with the research carried out by Matthys, Vaeyens, Vandendriessche, Vandorpe, Pion, Coutts, Lenoir and Philippaerts ${ }^{13}$, which reflected that category (age 
group) influences the stage at which distinguishing anthropometric variables of players' performance levels are identified.

A discriminatory analysis indicated that five variables could help distinguish between regional and national players. This model combines tests that assess explosive strength (CMJ) and speed $(10 \times 5 \mathrm{~m})$ with anthropometric variables (body mass, hand length and trochanter height), accounting for $81.9 \%$ of the overall variance. The parameters highlighted by the discriminatory analysis correspond to anthropometric characteristics and physical performance demands, viewed as essential in senior handball players $^{2,23,29}$. Three of the five variables were associated with PHV. It must be noted, however, that variation of maturity status did not feature as a variable in the model. Nevertheless, our model fails to account for $18 \%$ of the variance. This could be explained by the complexity of handball, and the fact that certain tactical and technical aspects have not been dealt with in this study. Lidor et al. ${ }^{30}$ indicated that assessments of technical skills would need to be found in light of the difficulty involved in deciding which systematic approach, among those presented in recent studies, would be better suited for the purpose. With this study it has been advanced that physical performance and anthropometric characteristics may be used to distinguish players that will potentially achieve high performance levels playing handball.

\section{Main findings and conclusion}

This study analyzed the evolution of the sporting performance of young handball players for 13 years; $28.7 \%$ of the participants assessed in the 1998/1999 season reached elite levels.

As regards the first objective specified above and taking into account the results derived from the data analysis, we conclude that gender conditions performance-related variables and even more so in the case of anthropometric variables (height, arm span, trochanter height, thigh girth and leg girth) with a greater impact on males than on females. The physical performance tests of vertical jump (SJ and CMJ with/without arm) and the 10x5 m shuttle run were the most influential for both gender.

As regards the second objective, it should be noted that the selection of young talent in handball requires the combination of five variables (CMJ with arm, body mass, 10x5 m shuttle run, dominant hand length and trochanter height), which would contribute to distinguish between regional and national players successfully, with a predictive accuracy of $81.9 \%$ for all players.

\section{References}

1. Matthys SP, Fransen J, Vaeyens R, Lenoir M, Philippaerts R. Differences in Biological Maturation, Anthropometry and Physical Performance between Playing Positions in Youth Team Handball. J Sports Sci. 2013; 1-9.

2. Mohamed H, Vaeyens R, Matthys S, Multael M, Lefevre J, Lenoir M, Philippaerts R. Anthropometric and Performance Measures for the Development of a Talent Detection and Identification Model in Youth Handball. J Sports Sci. 2009; 27: 257-266.
3. Abbott A, Collins D. Eliminating the Dichotomy between Theory and Practice in Talent Identification and Development: Considering the Role of Psychology. J Sports Sci. 2004; 22: 395-408.

4. Pearson D, Naughton G, Torode M. Predictability of Physiological Testing and the Role of Maturation in Talent Identification for Adolescent Team Sports. J Sci Med Sport. 2006; 9: 277-287.

5. Williams AM. Perceptual Skill in Soccer: Implications for Talent Identification and Development. J Sports Sci. 2000; 18: 737-750.

6. Elferink-Gemser MT, Visscher C, Lemmink KA, Mulder T. Multidimensional Performance Characteristics and Standard of Performance in Talented Youth Field Hockey Players: A Longitudinal Study. J Sports Sci. 2007; 25: 481-489.

7. Till K, Cobley S, O'Hara J, Brightmore A, Cooke C, Chapman C. Using Anthropometric and Performance Characteristics to Predict Selection in Junior UK Rugby League Players. J Sci Med Sports. 2011; 14: 264-269.

8. Karalejic M, Jakovljevic S, Macura M. Anthropometric Characteristics and Technical Skills of 12 and 14 Year Old Basketball Players. J Sports Med Phys Fitness. 2011; 51: 103-110.

9. Buchheit M, Mendez-Villanueva A. Reliability and Stability of Anthropometric and Performance Measures in Highly-Trained Young Soccer Players: Effect of Age and Maturation. J Sports Sci. 2013; 1-12.

10. Huijgen BC, Elferink-Gemser MT, Lemmink KA, Visscher C. Multidimensional Performance Characteristics in Selected and Deselected Talented Soccer Players. Eur J Sports Sci. 2012; 1-9.

11. Till K, Cobley S, O’Hara J, Chapman C, Cooke C. A Longitudinal Evaluation of Anthropometric and Fitness Characteristics in Junior Rugby League Players Considering Playing Position and Selection Level. J Sci Med Sports. 2012.

12. Ingebrigtsen J, Jeffreys I, Rodahl S. Physical Characteristics and Abilities of Junior Elite Male and Female Handball Players. J Strength Cond Res. 2013; 27: 302-309.

13. Matthys SP, Vaeyens R, Vandendriessche J, Vandorpe B, Pion J, Coutts AJ, Lenoir M, Philippaerts RM. A Multidisciplinary Identification Model for Youth Handball. Eur J Sports Sci. 2011; 11: 355-363.

14. Visnapuu M, Jürimäe T. Relations of anthropometric parameters with scores on basic and specific motor tasks in young handball players. Percept Mot Skills. 2009; 108: 670-676.

15. le Gall F, Carling C, Williams M, Reilly T. Anthropometric and Fitness Characteristics of International, Professional and Amateur Male Graduate Soccer Players from an Elite Youth Academy. J Sci Med Sports. 2010; 13: 90-95.

16. Zibung M, Conzelmann A. The Role of Specialisation in the Promotion of Young Football Talents: A Person-Oriented Study. Eur J Sports Sci. 2012; 1-9.

17. Ross WD, Marfell-Jones MJ. Kinanthropometry. Physiological testing of elite athlete. London. Human Kinetics. 1991; 223-308.

18. Mirwald RL, Baxter-Jones AD, Bailey DA, Beunen GP. An Assessment of Maturity from Anthropometric Measurements. Med Sci Sports Exerc. 2002; 34: 689-694.

19. Adam C, Klissouras V, Ravazzolo M, Renson R, Tuxworth W. EUROFIT: European Test of Physical Fitness. Rome, Italy: Council of Europe, Committee for Development of Sport 1988. 
20. Leger L, Mercier D, Gadoury C, Lambert J. The Multistage 20 Metre Shuttle Run Test for Aerobic Fitness. J Sports Sci. 1988; 6: 93-101.

21. Malina RM, Cumming SP, Morano PJ, Barron M, Miller SJ. Maturity Status of Youth Football Players: A Noninvasive Estimate. Med Sci Sports Exerc. 2005; 37: 1044-1052.

22. Vaeyens R, Malina RM, Janssens M, Van Renterghem B, Bourgois J, Vrijens J, and Philippaerts RM. A Multidisciplinary Selection Model for Youth Soccer: The Ghent Youth Soccer Project. Br J Sports Med. 2006; 40: 928-934.

23. Gorostiaga E, Granados C, Ibanez J, Izquierdo M. Differences in Physical Fitness and Throwing Velocity among Elite and Amateur Male Handball Players. Int J Sports Med. 2005; 26: 225-232.

24. Skoufas D, Kotzamanidis C, Hatzikotoylas K, Bebetsos G, Patikas D. The Relationship between the Anthropometric Variables and the Throwing Performance in Handball. J Hum Mov Stud. 2003; 45: 469-484.

25. Zapartidis I, Vareltzis I, Gouvali M, Kororos P. Physical Fitness and Anthropometric Characteristics in Different Levels of Young Team Handball Players. TOSSJ. 2009; 2: 22-28.

26. Hasan A, Reilly T, Cable N, Ramadan J. Anthropometric Profiles of Elite Asian Female Handball Players. J Sports Med Phys Fitness. 2007; 47: 197-202.

27. Roescher C, Elferink-Gemser M, Huijgen B, Visscher C. Soccer Endurance Development in Professionals. Int J Sports Med. 2010; 31: 174-179.

28. Milanese C, Piscitelli F, Lampis C, Zancanaro C. Anthropometry and Body Composition of Female Handball Players According to Competitive Level Or the Playing Position. J Sports Sci. 2011; 29: 1301-1309.

29. Vila H, Manchado C, Rodriguez N, Abraldes JA, Alcaraz PE, Ferragut C. Anthropometric Profile, Vertical Jump, and Throwing
Velocity in Elite Female Handball Players by Playing Positions. J Strength Cond Res. 2012; 26: 2146-2155.

30. Lidor R, Falk B, Arnon M, Cohen Y, Segal G, Lander Y. Measurement of talent in team handball: the questionable use of motor and physical tests. J Strength Cond Res. 2005; 19(2): 318-325.

\section{Acknowledgments}

The authors would like to thank the Galician Handball Federation (Galicia, Spain) and all the coaches involved in this study for their collaboration and unconditional support. No financial assistance was obtained for this project.

\section{Corresponding author}

Jose $\mathrm{M}^{\mathrm{a}}$ Cancela

Faculty of Education and Sport Sciences. University of Vigo. Spain.

Faculty of Education and Sport Sciences. C. A Xunqueira, s/n, 36005. Pontevedra, Spain

Email: chemacc@uvigo.es

Manuscript received on March 03, 2016

Manuscript accepted on June 12, 2016

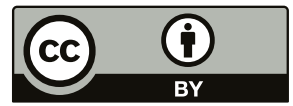

Motriz. The Journal of Physical Education. UNESP. Rio Claro, SP, Brazil - eISSN: 1980-6574 - under a license Creative Commons - Version 3.0 